\title{
LA VIDA INTELECTUAL CREADORA Y LA REALIZACIÓN DE «LO MEJOR» DESDE LA VISIÓN FILOSÓFICA DE JULIÁN MARÍAS ${ }^{1}$
}

\author{
JOSÉ RAÚL ASIMBAYA SOCASI \\ Universidad Católica de Cuenca - Ecuador \\ Studium Theologicum Franciscanum «Cardenal Echeverría» - Ecuador
}

CONRADO DE JESÚS GIRALDO ZULUAGA

Universidad Pontificia Bolivariana - Colombia

RESUMEN: El presente trabajo pretende indagar el problema de la vida intelectual creadora en el ámbito universitario y el impulso de la realización de «lo mejor» con visión, claridad de pensamiento y razón de la vida desde el pensamiento mariano y superar de este modo el peligro de quedarse instalado en el academicismo filosófico, que enfatiza la erudición, la acumulación de información más que el aprendizaje, la relaciones interpersonales, el pensamiento propio u otras maneras de ver la realidad.

PALABRAS CLAVE: Marías; vida intelectual creadora; lo mejor; visión responsable; academicismo.

\section{Creative intellectual life and the fulfilment of "the best" from the philo- sophical vision of Julián Marías}

ABSTRACT: The present work tries to investigate the problem of the creative intellectual life in the university environment and the impulse of the fulfilment of "the best» with responsible vision, clarity of thought and the reason of the life from Marian thought and recover in this way the danger of staying installed in the philosophical academicism which emphasizes erudition, the accumulation of information rather than learning, interpersonal relationship, one's own thinking or other ways of seeing reality.

KEY WORKS: Marías; creative intellectual life; the best; responsible vision; academicism.

Marías reconoce el insuperable estudio y la fuerza intelectual de su maestro Ortega sobre la misión de la Universidad, a él se remite para comprender esta compleja realidad en nuestros días. En su obra El intelectual y su mundo, realiza una breve explicación acerca de las funciones de la Universidad, pero advierte la necesidad de pasar de la vida académica centrada en la investigación hacia lo que él llama «vida intelectual creadora». Para el filósofo español:

«La palabra investigación está demasiado cargada de resonancias de laboratorio o de seminario filológico; es decir, pesa en ella excesivamente el aspecto "técnico" del trabajo, la idea de "taller"... La vida intelectual creadora es el contacto vivo con los problemas vivos, el funcionamiento de la actividad intelectual ejercitada en toda su desnudez, la exposición de un pensamiento que se está haciendo, la convivencia real entre maestros y discípulos, es decir,

1 Este artículo surge como una continuación de la investigación realizada para la tesis doctoral que lleva por título: «La vida intelectual creadora en el ámbito universitario. Del academicismo filosófico al saber radical en filosofía a partir de la propuesta personalista de Julián Marías», presentada en la Universidad Pontificia Bolivariana por el Mgs. y Dr. José Raúl Asimbaya Socasi con la dirección del Dr. Conrado De Jesús Giraldo Zuluaga. 
el encuentro efectivo de varias generaciones en las cosas mismas, en la fricción sobre los mismos problemas»².

Con otras palabras: la vida intelectual creadora es un modo de vida orientado a la innovación permanente dentro y fuera del ámbito universitario cuya base es la actitud abierta al aprendizaje, la «visión responsable» de la realidad y «formas nuevas de vida intelectual, de trabajo común, de docencia incluso ${ }^{3}$.

Marías hizo su vida filosófica fuera del ambiente universitario, de esa experiencia concluyó que las formas privadas de docencia, —refiriéndose a los cursos pagados que realizaba Zubiri, a los cursos o conferencias que Ortega y él mismo promovieron en el Instituto de Humanidades, fundado en 1948, donde concurría mucha gente-, nunca pueden sustituir a la Universidad, porque están pensados para grupos y áreas de conocimientos específicos ${ }^{4}$. Para que la Universidad promueva la vida intelectual creadora, Marías plantea dos razones: «la primera, evitar la inercia, el hacer lo de siempre, como si estuviese justificado y fuese obvio; la segunda, eliminar la petulancia y la fácil satisfacción, para sustituirlas por lo más fecundo de que dispone el hombre: el descontento» ${ }^{5}$. El docente universitario está llamado a pensar constantemente en cómo repercutir en la vida de las personas y el bien común. El saber y la responsabilidad van tomados de la mano; por eso, la razón de la universidad y del docente universitario son las personas. Ortega y Gasset al hacer un estudio sobre la misión de la Universidad manifiesta: «En vez de enseñar lo que, según un utópico deseo, debería enseñarse, hay que enseñar sólo lo que se puede enseñar, es decir, lo que se puede aprender» ${ }^{6}$. El reto está en organizarse de otra manera y emprender la vida intelectual creadora con visión, claridad de pensamiento y la razón de la vida.

\section{IMPORTANCIA DE LA VISIÓN PARA HACER FILOSOFÍA}

Marías en su obra Cervantes clave española (2003) infunde optimismo al intelectual con un importante descubrimiento cuando aparentemente un asunto está indagado o se piensa que ya no hay que decir por los innumerables estudios realizados. Creencia muy frecuente que causa descontento por falta de novedad. Marías razona y expresa:

«Pienso que siempre se puede hacer algo que no esté hecho, incluso sobre asuntos tratados de un modo que parece exhaustivo. Nada es exhaustivo, porque nada real se puede agotar. Todas las ideas, teorías, interpretaciones,

2 MARÍAs, J. (1956). El intelectual y su mundo. Buenos Aires: Atlántida, pp. 82 y 83.

MARÍAs, J., El intelectual y su mundo, p. 96.

4 Marías, J., El intelectual y su mundo, p. 94.

5 MARías, J., El intelectual y su mundo, pp. 95-96.

6 Ortega y Gasset, J. (1959). El libro de las misiones. Madrid: Espasa-Calpe, p. 82. 
aun siendo verdaderas, dejan fuera una enorme porción de la realidad, que va más allá de todas ellas.

En definitiva, se trata de algo muy sencillo, que es elegir una perspectiva propia. Si se mira la realidad desde un punto de vista personal, desde la situación de cada uno, automáticamente resulta que se ve algo nuevo, porque las perspectivas no son intercambiables ni equivalentes, sino por el contrario, irreductibles; y a la vez comunicables, y esta es la justificación de que se hable o se escriba» ${ }^{7}$.

Si hubiera una sola manera de ver y comprender la vida humana, sobraría este estudio; sin embargo, siempre hay posibilidades para producir conocimiento buscando «lo mejor» y que no sea arcaico, basta darse cuenta de lo que los filósofos han pensado en su situación concreta e histórica. Marías no es la excepción, coherente con su manera de pensar y escribir con fluidez en sus obras para todo tipo de lectores, deja una puerta abierta para indagar la vida humana, iniciada en su obra Introducción a la filosofía (1947) y comprendida con mayor claridad en otra obra suya, Antropología metafísica (1970), base extraordinaria para posteriores publicaciones. La clave está en seguir con detenimiento el ir y venir del pensamiento de Marías; da la impresión que redunda sobre lo mismo, pero en cada obra hay continuidad y una particularidad, jamás pierde de vista la vida humana; la retoma y vuelve a repensar desde diferentes cuestiones con originales reflexiones.

Marías es un filósofo visual, continuando con la tradición filosófica occidental y el pensamiento orteguiano, valora la vista, pero con un ingrediente que interpela al filósofo o al intelectual: la responsabilidad. En pocas palabras esta implica hacerse cargo de la circunstancia o saber a qué atenerse respecto a la situación en que se está ${ }^{8}$, sin perder la libertad y la evidencia sobre lo que se ve. La libertad es inseparable de la verdad, son principios fundamentales de la vida humana — la de cada cual_; en la verdad es donde se aloja la responsabilidad y un uso adecuado de la razón para reaccionar ante lo que pasa en el mundo, lo que nos pasa, me pasa y me afecta ${ }^{9}$. Esto es hacer filosofía con «visión responsable», un acierto de Marías para manifestar desde su vida, el oficio del filósofo responsable, creativo e innovador. Pero de inmediato surge una inquietud: ¿por qué primariamente la vista y no otros sentidos? Marías en su ensayo La interpretación visual del mundo (1956) y posteriormente en Antropología Metafísica, argumenta lo siguiente:

«La vista es el sentido del mundo o si se prefiere, de la mundanidad... [Ú]nicamente la vista hace presente las cosas ausentes para los otros sentidos, es decir, lejanas. Y esa presencia no consiste en suprimir la lejanía, en

\footnotetext{
7 Marías, J. (2003). Cervantes clave española. Madrid: Alianza Editorial, pp. 9 y 10.

8 MARías, J. (1962). Introducción a la filosofía. Madrid: Revista de Occidente, p. 175.

9 Restrepo, C. (2013). La vida humana. Biografía y estructura empírica. Medellín: Universidad Pontifica Bolivariana, pp. 68 y 74.
} 
anularla, sino al revés: la vista nos pone presente lo que no está aquí, sino ahí $o$ allí; es decir, la presencia visual de la lejanía en cuanto tal» ${ }^{10}$.

Marías plantea la exploración del mundo — desde uno mismo- a través de la vista en permanente movimiento de ida y vuelta hasta llegar a la verdad y generar una forma nueva de saber. Como pensador con profundo sentido humanista, incluye a los no videntes en este hacer y encuentra que el ciego realiza interpretaciones visuales, pero con la estructura visual que el vidente le proporciona para comprender el mundo en que está viviendo. Para Marías:

«El lenguaje, las imágenes, las metáforas, incluso muchas conexiones lógicas, están referidos a la visualidad. Al ciego le falta, claro es, la intuición sensible de todo eso, no lo ve pero opera con todas esas estructuras visuales. Literalmente, el ciego vive en un mundo visual, que se ve con los ojos de los demás, es decir, con lo que su vida tiene de vida colectiva» ${ }^{11}$.

Es un planteamiento muy audaz, claramente evidencia que la visión y el pensamiento están interconectados; no tiene sentido lo uno sin lo otro, indistintamente de la condición humana, entendida esta como una manera de estar en el mundo. ¿Qué sería del hombre sin visualidad? Sencillamente no habría innovación, otra perspectiva — «la mía, la tuya, la que aquél»- como sostiene Marías en su obra Introducción a la filosofía ${ }^{12}$, para interpretar no sólo lo que las cosas son sino también la realidad humana, «lo que hacemos». Barsallo en la Revista Cuenta y Razón, fundada por Julián Marías en 1981, refiriéndose al filósofo español expresa: "Siguiendo a Ortega, Marías decía que ver es pensar con los ojos» ${ }^{13}$. Una metáfora que alude a la necesidad de mirar la realidad y filosofar a partir de ella para ejercer presión y saber qué hacer. Los ojos nos ponen en relación con el mundo diverso y complejo, y por su luminosidad realizamos aprehensiones e interpretaciones, decimos lo que vemos sin apartarnos de la verdad, desocultamos la realidad con preguntas, damos un uso a las cosas y ponemos en movimiento la vida intelectual creadora. Marías, inspirándose en la vida de su amigo José Manuel Blecua, uno de los mayores estudiosos de la literatura española, menciona: "Creo que la función del profesor, sobre todo universitario, es pensar con sus estudiantes, ante ellos y en su compañía; es la única manera de que el pensamiento se contagie» ${ }^{14}$.

La visión de Marías es sucinta pero de gran hondura, con cortesía sugiere reflexionar sobre el oficio del filósofo y el intelectual en el ámbito universitario;

10 MARÍAs, J. (1958). El oficio del pensamiento. Ensayos. Madrid: Nueva Almagro, pp. 53 y 55.

11 Marías, J. (1970). Antropología Metafísica. La estructura empírica de la vida humana. Madrid: Revista de Occidente, pp. 142 y 143.

12 MARías, J., Introducción a l filosofía, p. 445.

13 Barsallo, A., «Marías, crítico de cine personalista», en: Cuenta y Razón, No. 30, 2014, 37. http://cuentayrazon.com/wp-content/uploads/2016/05/revista30.pdf

14 Marías, J., «In Memorian. Cómo veo a José Manuel Blecua», en Cuenta y Razón, No. 28, 2013, 124. http://cuentayrazon.com/wp-content/uploads/2016/05/revista28.pdf 
visualiza el alcance de hacer filosofía juntos, la relación de proximidad y el impulso del pensamiento filosófico dentro de una concreta circunstancia humana como es la educación. Para que esto ocurra, Marías en su obra Sobre el Cristianismo (1998) escribe:

«Hay que intentar, si se quiere comprender una filosofía, situarse dentro de ella, de tal manera que al exponerla nos parezca justificada. No es menester - sería un profundo error- tratar de mostrar la deficiencia o falsedad de una doctrina sin tratar primero de entenderla. Hay que hacer un intento de justificarla, de presentarla desde dentro, no para después salirse de ella y refutarla - palabra antipática si las hay_, sino más bien para seguir dentro de ella y, al intentar tomarla en serio y pensarla a fondo, ver si efectivamente nos lleva a alguna parte o si tropezamos con alguna dificultad que nos obliga a ir más allá» ${ }^{15}$.

Marías muestra con claridad en qué consiste su hacer filosófico: primero, situarse dentro de la filosofía; segundo, entenderla para discrepar y dar continuidad; tercero, llegar a un resultado con una perspectiva propia. En el párrafo de arriba, hay dos preguntas esenciales para filosofar: ¿Qué hacer? ¿Para qué hacer? Hemos recibido una tradición filosófica a través de la Universidad, no por eso vamos a dejar de hacer filosofía. Esta es una actividad humana que se hace, que acontece. ${ }^{16}$ Con razón Marías exhorta a ver, pensar a fondo y entender de antemano una doctrina para saber qué hacer y evitar la mera opinión. Si por ejemplo alguien quisiera «refutar» a Marías, debería leer sus obras y además ubicarlo en la tradición filosófica que viene de Grecia y en la «Escuela de Madrid» a la que perteneció, y de la cual emergió la filosofía española con meditaciones profundas de connotados pensadores y maestros de Marías, entre ellos: Unamuno, Ortega, Morente, Zubiri y José Gaos. ${ }^{17}$ Una labor colosal que exige esmero y conocimiento sobre estos autores que emprendieron otra forma de hacer filosofía, ya no exclusivamente desde la razón sino también desde la vida humana en conexión con el mundo. Importa saber que sin visión mental no hay filosofía. Es necesario ver e ir más allá de lo que hay para hacer filosofía.

\section{LA CLARIDAD ES CORTESÍA DEL FILÓSOFO}

Marías aprendió de Ortega que la claridad es cortesía del filósofo; Ortega lo menciona en su obra ¿Qué es filosofía?, y Marías lo hace en el prólogo a la traducción inglesa de su libro Historia de la Filosofía. Escribe Ortega:

15 Marías, J. (1998). Sobre el cristianismo. Barcelona: Editorial Planeta, p. 138.

16 Marías, J., Introducción a la filosofía, p. 7.

17 Marías, J. (1969). Miguel de Unamuno. La Escuela de Madrid. La imagen de la vida humana. Madrid: Revista de Occidente, Tomo V, p. 223. 
«Pienso que el filósofo tiene que extremar para sí propio el rigor metódico cuando investiga y persigue sus verdades, pero que al emitirlas y enunciarlas debe huir del cínico uso con que algunos hombres de ciencia se complacen, como Hércules de feria, en ostentar ante el público los bíceps de su tecnicismo ${ }^{18}$.

La consigna de Ortega es sugerente al momento escribir y comunicar el pensamiento filosófico: hacerlo sin arrogancia académica, con un lenguaje que entiendan todos, especialistas y no especializados. Cabe preguntarse: ¿Para qué hablar o escribir con términos rebuscados sobre un asunto que a lo mejor no requiere de tanto enredo para comprender? Ortega revela una lección que aprender: rigurosidad en la indagación, pero también claridad en el uso del lenguaje para que otros comprendan y emprendan la aventura de pensar. Esto Marías, discípulo de Ortega, lo ejercita recurrentemente en todas sus obras con la siguiente pregunta: ¿Qué quiere decir esto? Sin duda alguna, constituye una estrategia para justificar lo que se dice, elegir entre las posibilidades y comprender la realidad desde un punto de vista personal e histórico. Marías, recordando los cursos informales de Filosofía que él desarrollaba con sus compañeras universitarias y asumiendo en esa experiencia docente la frase de Ortega «la cortesía del filósofo es la claridad», escribe:

«No existía ninguna complacencia en lo que Ortega mismo había llamado una vez "la lujuria de la mental oscuridad". Quiero decir con esto que mis alumnos pretendían entender todo lo que yo les enseñaba y que era nada menos que la totalidad de la historia de la filosofía de Occidente; me pedían que lo aclarara todo, lo justificara todo; que mostrara por qué cada filósofo pensaba lo que pensaba, y que ello era coherente, y si no lo era, por qué. Pero esto significa que yo tenía que entenderlo, si no previamente, sí a lo largo de la clase. Nunca he tenido que esforzarme tanto, ni con tanto fruto, como ante aquel auditorio de catorce o dieciséis muchachas florecientes, risueñas, a veces burlonas, de mente tan fresca como la piel, aficionadas a discutir, con afán de ver claro, inexorables. Nadie, ni siquiera mis maestros, me ha enseñado tanta filosofía» ${ }^{19}$.

Marías descubre el valor de la claridad en filosofía mucho antes de publicar sus obras; siendo aún estudiante se apropió plenamente de la expresión «la cortesía del filósofo es la claridad», la ejercitó ante un grupo de compañeras que tenían muchas inquietudes y afán de ver claro la doctrina de los filósofos a lo largo de la historia de la filosofía. Un desafío que asumió con esfuerzo, investigación y responsabilidad; debía hacer inteligible lo que enseñaba. Sin sospechar siquiera, estaba trazando el camino para el nacimiento de su monumental obra: Historia de la Filosofía. Obra que debe a su esposa Lolita Franco, una de las chicas que siguió sus cursos informales y puso a disposición los apuntes para que Marías escribiera el libro, con un contenido claro e inteligible. Pinillos en el prólogo de la obra La visión responsable de Raley (1977) menciona:

18 Ortega y Gasset, J. (1969). ¿Qué es filosofía? Madrid: Revista de Occidente, p. 20.

19 Marías, J. (1980). Historia de la filosofía. Madrid: Revista de Occidente, xxxvi- xxxvii. 
«Marías escribe un castellano perfecto: sabe encontrar el giro adecuado para expresar en pocas palabras lo que se diluiría en muchas; apura los recursos del idioma antes de recurrir a tecnicismos forzados y, en definitiva, la claridad es consustancial a su exposición ${ }^{20}$.

Esto ilustra la necesidad de escribir o hacer teoría para que los lectores entiendan y repiensen lo que han leído; ahí se hace evidente la claridad del filósofo, el gusto por el uso de la lengua española y el punto de vista de cada cual sobre lo que ve en el mundo sin deformar o describir con términos que entiende solamente el que lo inventó. Marías expresa lo siguiente respecto a los neologismos:

«La realidad suele ser otra: el nombre artificioso y «técnico», forjado expresamente para designar una cosa problemática, permite "manejarla", operar mecánica y tal vez automáticamente con ella, hacerla funcionar como magnitud conocida y consabida en nuevos contextos y situaciones, apelar a ella como solución y principio explicativo, cuando tal vez reclama explicación y esclarecimiento. El neologismo cuando se convierte en prurito, no solo violenta la condición misma de la lengua, sino que transforma la teoría en una especie de "magia verbal" ${ }^{21}$.

De ningún modo Marías se opone a la invención de nuevos términos filosóficos; él mismo en su vida filosófica introdujo algunos, entre ellos: corporeidad, feminidad, masculinidad, persona, mundanidad, futurizo, visión responsable. Le llama la atención el uso excesivo de palabras nuevas creyendo que con eso se explica la realidad, diríase también, creyendo que con eso se perfecciona el lenguaje filosófico; tamaño desacierto, a la final, hay imposición de una manera de pensar y manejo términos en los lectores, sin capacidad de sospecha. Lo propio de la filosofía es ejercitar el pensamiento en libertad, articulado con lo que acontece en la vida humana para explicar clara y firmemente lo que hay. ¿Y si no hay? Lo sensato es no inventar sino indagar y justificar. "La magia verbal» a la que se refiere Marías, tiene que ver con el pensamiento especulativo, copioso rodeo para explicar o teorizar la realidad y con palabras de difícil interpretación o traducción. Escribe Marías a propósito de la publicación de uno de sus primeros libros en inglés, Miguel de Unamuno, esta preocupación:

«Siempre que un libro mío cruza la frontera de una lengua siento un impulso de inquietud y zozobra; porque, quiérase o no, se va a convertir en otro libro, va a decir a sus lectores otras cosas que las que yo escribí. En efecto, las palabras escritas son solo las que hacen falta; el resto de lo que quiero decir se calla por sabido, porque ya lo sabe el lector, que pertenece a la misma sociedad que el autor; pero cuando un libro se traduce a otra lengua, cuando habla a personas que no comparten con el que escribe tantos "secretos de familia", no puede contar con ese contexto, y su texto queda abandonado a sí mismo. No es esto lo peor, sin embargo. El lector extranjero pone el texto en su propio

20 Raley, H. (1977). La visión responsable-La filosofía de Julián Marías, trad. César Armando Gómez. Madrid: Espasa, pp. 24 y 25.

${ }^{21}$ Marías, J., Oficio del pensamiento, p. 139. 
contexto; es decir, lo recibe y lo entiende desde ciertos supuestos con los que el autor no había contado cuando escribió. Esto es, el escritor se encuentra con que está diciendo más y menos de lo que originariamente había escrito.

Las mismas palabras, los giros tienen distintas resonancias, provocan otras asociaciones. He hecho a veces el experimento de leer una página mía en su original y en dos o tres traducciones extranjeras: suena de otras tantas maneras, tiene diverso tono sentimental, incluso diferente significación intelectual» ${ }^{22}$.

Más que un desahogo del autor, lo expuesto es una experiencia de la vida para escritores, profesores y estudiantes que recurren a libros traducidos de filosofía; bien traducidos e interpretados admirablemente, dan gusto e interés por entender en qué consiste el quehacer del autor al hacer filosofía; y si no ocurre así, lo más probable es que sean descartados o ignorados por el uso lingüístico de difícil comprensión. Muy importante entonces, pensar y escribir con claridad e inteligibilidad, colocando palabras que despierten inquietud y deseo de filosofar; y además, indagar yendo a las fuentes por las dificultades que expone Marías respecto a las traducciones.

\section{LA REALIZACIÓN DE «LO MEJOR»}

En uno de sus últimos libros, Tratado de lo mejor. La moral y las formas de la vida (1995), da cuenta Marías de algo necesario en la vida de cada cual: la realización de lo mejor ante una "pluralidad de posibilidades entre las que hay que elegir». Es responsabilidad de cada persona el acierto o el error sobre lo que elige. «Es probable que los conceptos de acierto y error no pertenecen estrictamente a la moral, sino que tienen que ver con la inteligencia o la destreza; pero no se puede omitir este aspecto de la moralidad, porque tiene inmediata repercusión en las consecuencias, y por tanto en la conexión de los ingredientes de la vida» ${ }^{23}$. Esto constituye una visión filosófica distinta para "plantear los problemas de la moral». Escribe Marías en el Prólogo de esta obra:

«La milenaria tradición de la ética ha insistido con casi total unanimidad en la idea del bien, en la condición de lo bueno. Creo que el influjo del pensamiento helénico y el no menor de la teología, centrada en la noción de Dios, son los motivos de esa preponderancia. Pero acaso se encuentre que el ámbito de la moralidad de la vida humana — de eso se trata, y no de otra cosa- es precisamente lo mejor, decisivo en la ordenación de la conducta y, todavía más, en la realización de esa operación que es vivir» ${ }^{24}$.

La noción de lo mejor tiene que ver con lo que hace el sujeto en relación con las cosas y con otras personas. En esta relación o forma de instalación surge la

22 MARías, J., Miguel de Unamuno. La Escuela de Madrid. La imagen de la vida humana, p. 215.

23 Marías, J. (1995). Tratado de lo mejor. La moral y las formas de la vida. Alianza: Madrid, pp. 25 y 26.

${ }^{24}$ Marías, J., Tratado de lo mejor, p. 11. 
moralidad o inmoralidad; que a juicio de Marías, las meras regulaciones y la apelación a los valores no son suficientes ${ }^{25}$. ¿Por qué? El hombre es responsable de su vida; la realiza de mejor o peor manera, depende de lo que elige o prefiere y de la visión personal respecto a lo quiere ser y lo que quiere hacer. Marías afirma que: «Vivir es preferir. Hay que tener y darse razones para hacer una cosa y no otra» ${ }^{26}$. En esa forma de vivir resulta vital el ejercicio de la libertad y la justificación de los actos para «saber a qué atenerse, saber qué hacer y en consecuencia saber por qué y para qué hacerlo» ${ }^{27}$. Lo cual no se hace en abstracto, sino desde cada persona, desde la situación social en que se vive e incluso desde la historia para comprender las formas de la vida y las vigencias sociales en pueblos y épocas diferentes, con sus aciertos y errores.

A juicio de Marías: «El estudio de la moralidad tiene que ir más allá del plano de la estructura analítica para llegar a la empírica ${ }^{28}$, "propia de la vida humana tal como se realiza en lo que llamamos el hombre ${ }^{29}$, "de carne y hueso», que "no está simplemente en el mundo (artículo determinativo), sino en este mundo (pronombre demostrativo)» ${ }^{30}$. "haciendo esto y no lo otro, dadas las circunstancias ${ }^{31}$. Marías plantea una perspectiva ética basada en la responsabilidad de elegir y decidir por lo mejor entre las posibilidades que aparecen en nuestras vidas, en mi vida, en la vida de cada cual. Vivir es siempre hacer lo mejor posible; organizar de otra manera las cosas; dar paso a otras maneras de ver y comprender las cosas, y las realidades humanas. En este proceso, resulta inevitable lo que tanto insiste Marías en sus obras: ver al hombre como persona, como «alguien corporal». «Alguien, en modo alguno algo. La persona vive, se proyecta, imagina, duda, interroga, teme, desde su cuerpo inseparable, y por supuesto en el mundo, que es donde está, precisamente por su corporeidad ${ }^{32}$. Es una forma de instalación tal como la vivimos, «es decir, en un cuerpo y como hombre o mujer» ${ }^{33}$. Pasar por alto esta realidad personal, trae consigo el peligro constante de la despersonalización o la cosificación; se ve como si fuera «normal» o socialmente aceptado: la agresión, el vandalismo, el aborto, el enriquecimiento desmedido, el abandono, la corrupción política, las guerras, el hambre y demás formas de inmoralidad. Marías da cuenta que:

«Multitudes de contemporáneos nuestros creen —o intentan creer- que todo está permitido, porque es indiferente y no requiere justificación, y se

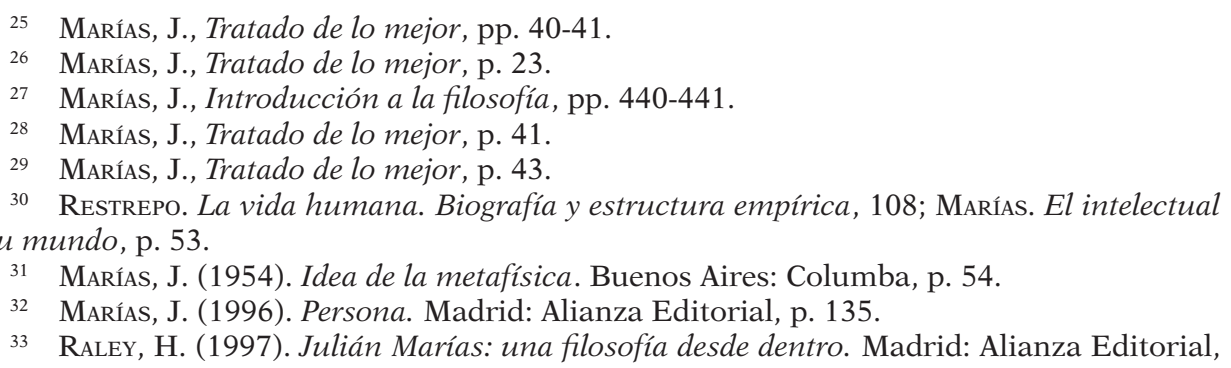

33 Raley, H. (1997). Julián Marías: una filosofía desde dentro. Madrid: Alianza Editorial, p. 132. 
sienten perdidos. Pocas veces se han dado tantas vidas "a la deriva", que se dejan llevar y cambian de rumbo sin ser capaces de dar razón de por qué lo hacen ${ }^{34}$.

La pérdida de libertad y el sentido mismo de la moralidad en la vida de cada cual, son asuntos que reclaman educar mejor a las nuevas generaciones desde la institución familiar, educativa, política, económica o religiosa. La realización de lo mejor nace o se fortalece cuando hay autenticidad; cuando no, se mira la vida de las personas como si no importara nada, lo cual expresa la falta de proyectar la vida personal con responsabilidad y la falta de formación intelectual y personal en las instituciones educativas. "Lo que se hace afecta a la vida humana»; por eso hay que pensar en qué respuesta dar y preferentemente liberadora e innovadora para repercutir en la vida de las personas. La vida humana no es una cosa sino proyección e innovación; esto de por sí, resulta vital, quizá con mayor razón, para los dedicados a la vida intelectual. Pero, ¿qué está pasando? La labor de los intelectuales está concentrada en otros menesteres que pensar e innovar. Marías en su obra Oficio del Pensamiento cuestiona esta realidad, formula preguntas que tiene que ver con la moralidad al afirmar que: "Ante una cuestión cualquiera ¿qué hace primariamente el intelectual? ¿Se pone a buscar bibliografía, se pone a leer libros viejos, busca el último artículo, se pone a pensar? ¿Por qué ocurre así? ¿Por qué el pensamiento ha pasado, de ser el atributo esencial y constitutivo del intelectual, a ser un fenómeno relativamente infrecuente?» ${ }^{35}$. Son preguntas que aguijonean a "ser actual y no arcaico» en la labor intelectual. Marías en tono firme asevera:

«Al intelectual no le es lícito mentir, y si miente debe perder el derecho a ser tratado como tal. El que no quiere enterarse, el que prefiere suponer que las cosas son de cierta manera, mejor que comprobar que son de otro modo, no es un intelectual» ${ }^{36}$.

El ejercicio de la vida intelectual alcanza su esplendor donde hay verdad justificada, innovación, creatividad y conciencia de continuidad, sin que esto signifique repetición de lo pensado, escrito o publicado, sino partir del punto al cual se ha llegado para dar un nuevo impulso desde de la situación en la que está cada quien. La de Marías, comprender la vida humana en cuanto acontecer biográfico e histórico, es decir como narración y como convivencia. Por eso hay moralidad, actualidad y futuro en sus obras. Lo mejor está unido a la vida vivida hasta el momento y a la visión responsable de la realidad; ambas entendidas y asumidas como un hacer, sencillamente porque ninguna teoría, razonamiento o acto empieza en cero. Si todo estuviera «dado o realizado», ¿cuál sería el sentido de vivir y de innovar? Es algo que varones y mujeres tienen que hacer y con responsabilidad. «Es esencial darse cuenta de que la vida, mientras dura, no está nunca cerrada; que las trayectorias continúan a

34 Marías, J., Tratado de lo mejor, p. 143.

35 Marías, J., Oficio del pensamiento, pp. 15 y 16.

36 Marías, J., El intelectual y su mundo, p. 31. 
lo largo de toda ella y, lo que es más importante, pueden iniciarse en cualquier momento ${ }^{37}$. La vida intelectual creadora es una de las trayectorias de la vida humana; por tanto se espera ver y encontrar lo mejor en libros, ensayos, artículos, revistas o periódicos. Sin embargo, esto no es muy frecuente, a pesar de haber muchas publicaciones; hay cantidad de información, pero desconectada de la historia e incluso lejos de hacernos entender la realidad para actuar y ser nosotros mismos. Se publican obras para ascender en el escalafón, mejorar el bienestar económico o elevar el «rating» a nivel personal e institucional, que para ejercer presión y provocar transformaciones en lo existente. En la vida intelectual de Marías, la búsqueda de lo mejor es notoria; cada obra recupera lo valioso de la historia y cada obra es mejorada una y otra vez con nuevas perspectivas que ejercen presión y conciencia crítica al abordar los problemas con verdad justificada, es decir, sin mentir o falsificar. Marías tenía muy claro que: «La innovación es la introducción de algo nuevo "en" lo que ya existía; no hay innovación sin tradición, no hay movimiento histórico sin esencial novedad ${ }^{38}$. Tradición e innovación son inseparables; ninguna teoría, razonamiento o acto empieza de cero. Siempre hay un pasado que está presente en nosotros mismos antes de dar un nuevo paso; de modo que, realizar lo mejor o hacer otra cosa distinta, implica ponerse a pensar e indagar lo que se ve y en cuestiones filosóficas resulta significativo, descubrir por dónde empieza cada autor su quehacer filosófico y qué quiere decir en sus obras. Filosofar no es «enseñar más» o transmitir lo que otros han dicho, sino pensar, interpretar y justificar lo que ve en la realidad desde un punto de vista personal para encontrar algo nuevo en el pensamiento de los filósofos del pasado próximo y remoto.

\section{El PELIGRo DE QUEDARSE INSTALADO EN EL ACADEMicismo FILOSÓFICO}

Marías nunca fue partidario del hacer filosófico basado en el almacenamiento de información, sino en la producción de pensamiento y el trato personal. Pensar y relaciones humanas de lo mejor, fueron claves para ejercitar una vida intelectual creadora y una «visión responsable» del hombre concreto. Esto da lugar a decir que filosofar es una actividad humana que supera el afán meramente informativo o erudito; quiérase o no, al momento de pensar, escribir o ejercer la docencia hay una realidad inevitable: la presencia de personas, incluido quien filosofa. Marías inicia la exploración y develamiento de la realidad persona con mayor profundidad desde su obra cumbre Antropología metafísica, anteriormente ya abrió el panorama en la Introducción a la Filosofía al describir la estructura de la vida humana; cuando publicó El mundo del mapa personal, Persona, La Felicidad Humana, esta realidad ya es bastante comprensible.

37 MARías, J. El tratado de lo mejor, p. 82.

38 Marías, J. El intelectual y su mundo, p. 120. 
Convencido de que la historia es fundamental para comprender la realidad buscada, Marías da cuenta y razón de la visión inadecuada que se ha tenido del hombre durante siglos. Afirma que desde hace dos mil quinientos años se pregunta erróneamente: ¿qué es el hombre? Pero la pregunta adecuada no es qué sino quién. Cuando alguien conocido - no algo_ llama a la puerta no preguntamos ¿qué es?, sino ¿quién es? La respuesta de quien llama es yo, acompañado de su voz, es decir de una circunstancia ${ }^{39}$. Es un descubrimiento valioso; válido no solamente para quien está detrás de la puerta sino también para el que está al frente, como ocurre en la relación profesor y alumno en el aula. Ambos están presentes, son «alguien», son «quien»; pero sucede que no saben «quiénes» son, por la masificación o por el academicismo filosófico, donde el maestro se preocupa de enseñar y el alumno de asimilar, no para pensar después por propia cuenta, sino para repetir; una acción que devasta la vida intelectual creadora y distorsiona la función del maestro como propiciador de la discusión filosófica, la indagación de la realidad para saber qué hacer y del trato personal. Esto no siempre fue así, pues en la antigüedad se hacía filosofía en las calles, las plazas, paseando en el ágora; el maestro dialogaba, discutía y argumentaba con los discípulos sobre asuntos de la vida pública; con la aparición de las universidades europeas a finales del siglo XI, esta relación cambió y de igual modo el hacer filosófico, el motivo de estudio ya no fue la vida pública sino autores de la tradición filosófica. La filosofía como modo de vida pasó a ser una disciplina y una profesión, sometida a presiones del Estado y a un currículo sin visión de la persona y «el contacto vivo con los problemas vivos». Los filósofos griegos se preocuparon del hombre, pero visto "desde afuera», como algo que "está ahí» ${ }^{40}$; posición que se mantuvo incluso en ulteriores profesionales de filosofía. Por eso en la teorización sobre quién es pierde de vista la condición personal; ven, hablan o escriben del hombre no como alguien sino como algo. No parten desde su vida, desde su historia, desde lo que hace y lo que le pasa ${ }^{41}$; lo cual conllevó al descubrimiento tardío de la realidad persona, en el siglo XX. Marías en su obra Antropología Metafísica, propone reformular la pregunta kantiana ¿qué es el hombre?, por dos preguntas radicales e irrenunciables:

«1) ¿Quién soy yo? 2) ¿Qué va a ser de mí? No se trata de «el hombre», ni de «qué», sino de «yo» y de un «quién». Y a esa pregunta no se puede contestar más que viviendo, con una respuesta ejecutiva. La segunda es también una pregunta personal: pregunto «qué», pero digo qué va a ser «de mí». La articulación del «quién» y el «qué» es precisamente el problema de la vida personal $»^{42}$.

Marías muestra esta evidencia desde lo experiencial, desde cuando cada uno intenta averiguar quién soy yo; que de por sí, constituye una tarea exploratoria

39 Marías, J., Antropología metafísica, p. 44.

40 Marías, J., Persona, p. 17.

41 Restrepo. La vida humana. Biografía y estructura empírica, p. 62.

42 Marías, J., Antropología metafísica, pp. 47 y 48. 
inagotable y una realidad que no está hecha del todo, porque hay que hacerla: siendo, viviendo, relacionándose y formulando otras maneras de ver las cosas. En la búsqueda de saber quién soy yo, hay necesidad de un tú, pero más allá de hacer el objeto de pensamiento. No se trata de imaginar ese tú, sino de pensar con él o con ella sobre la vida humana, sobre lo que está pasando o aconteciendo en el mundo. Pensar juntos es un ejercicio inexcusable en la actividad filosófica para compartir una idea, actividad, interés o incluso para innovar, mejorar las relaciones interpersonales o develar diversos problemas filosóficos. Escribe Marías en La Felicidad humana:

«Las cosas humanas piden justificación, hay que preguntarse el por qué. La justificación tiene que venir del proyecto mismo, del interés por algo. Y aquí irrumpe la condición amorosa del hombre, que casi nunca se ha tomado en serio, que se ha pasado por alto en la mayor parte de la historia del pensamiento. Siempre se ha buscado la peculiaridad del hombre, se ha hablado de su carácter inteligente, racional; todo esto es cierto, se dice que el hombre es animal racionale, pero nunca se dice que es animal amorosum ${ }^{43}$.

La posición de Marías pone en el tapete de la discusión filosófica un tema bastante desconocido en filosofía que en teología: el hombre como «criatura amorosa». Es un descubrimiento para indicarnos que el hombre ha sido creado para amar y con esto, el filósofo español, rompe la heredad de la tradición filosófica basada exclusivamente en lo racional, la actividad que realiza, que en la vida. Un asunto audazmente pensado de otra manera en principio por Ortega y continuado por Marías hasta llegar a un gran hallazgo: el tema de la persona, explorado en principio en su obra Introducción a la filosofía (1947) y con una visión distinta en Antropología metafísica (1970) y en otras obras que el propio Marías menciona: La mujer en el siglo XX y La mujer y su sombra; La felicidad humana; La educación sentimental; Razón de la filosofía; Mapa del mundo personal; Tratado de lo mejor; Una vida presente; Breve tratado de la ilusión ${ }^{44}$. En su obra Educación sentimental, preocupado por «la tosquedad del repertorio múltiple y variadísimo de las relaciones humanas, que no permite cultivarlas, ni verlas, y empobrecen indeciblemente una vida que podría alcanzar niveles admirables» ${ }^{45}$, propone retomar la educación sentimental, «uno de los núcleos en torno a los cuales se organiza la vida, y precisamente en sus estratos más profundos, donde se encuentran las raíces de casi todo lo demás» ${ }^{46}$. ¿Qué quiere decir esto? La vida es estar en el mundo con las cosas y también con los demás; por lo que, todo gira en torno a la relación afectiva y comprometida con las personas para ejercer presión sobre la realidad y transformarla, sin que las apetencias personales tales como ascensos, reconocimientos o bienestar económico sean lo prioritario. La satisfacción

43 Marías, J. (1989). La felicidad humana. Madrid: Editorial, p. 343.

44 Marías, J., Persona, pp. 10 y 11.

45 Marías, J. (1992). La educación sentimental. Madrid: Alianza Editorial, p. 10.

46 Marías, J., La educación sentimental, p. 10. 
de esas apetencias conlleva a no decir lo que se piensa; sencillamente porque son condicionamientos que supeditan. En la Educación sentimental, Marías visualiza: la vivencia de virtudes, la mejor referencia de cada persona para las demás, la comprensión de la realidad persona y su dignidad, y la necesidad de hacer algo concreto. Sólo ahí entonces tiene sentido las dos cuestiones que plantea el filósofo español: 1) ¿Quién soy yo? 2) ¿Qué va a ser de mí? El filósofo tiene que contagiar entusiasmo, amor al oficio de pensar, imaginación, ilusión, generosidad, amistad y otras maneras de ver las cosas. Escribe Marías:

«Un mínimo de generosidad es absolutamente necesario para toda relación personal si ha de ser fecunda y enriquecedora. La carencia o escases de ella es una causa frecuente del fracaso de relaciones familiares, amistosas, amorosas. (....). Hay una tendencia muy fuerte a "borrar" o "dar de baja" a la persona que nos ha defraudado, y en el fondo esto es un error. Por una parte, siempre es posible que esa persona vuelva; por lo menos, que vuelva a necesitarnos. Por otra parte, la teología enseña que todo hombre, mientras vive, es amigo actual o potencial de Dios» ${ }^{47}$.

La relación más importante que tenemos es con los demás; de modo que la posición de Marías es muy clara: recuperar la educación sentimental en la educación, la política, la familia, la intimidad personal y demás ámbitos a fin de dar transparencia a la vida y mostrar sentimientos favorables. ¿Qué quiere decir esto? En la relación personal hay que tomar en cuenta que el hombre está referido a la mujer y viceversa, por lo que, los vínculos de amistad, acogida, respeto y apoyo mutuo son esenciales para evitar la tosquedad, la falsedad en las relaciones personales y «el conformismo o censura interna» como denomina Marías a esta actitud ${ }^{48}$. La afectividad es tan valiosa como la mente y las manos; no parece juicioso, que la misión de los profesores sea cultivar la racionalidad humana, las habilidades y nada más. Asunto de honda preocupación por la calidad humana deplorable que estamos viendo en la vida pública. Marías, al reflexionar sobre la calidad personal en su obra Tratado sobre la convivencia humana, muestra lo que inspiran las personas en la relación próxima y la importancia de poner atención, tomar en serio lo que se ve y obrar en consecuencia. Escribe Marías:

«Hay personas que se ganan mi estimación y mi confianza a primera vista; hay otras a las que excluyo por haberlas visto mentir, insultar, calumniar, descomponerse patológicamente, exhibir un impúdico rencor, o una patente hipocresía ${ }^{49}$.

La experiencia personal de Marías permite ampliar el horizonte en las relaciones interpersonales. La vida de cada cual es vista e interpretada por otra persona de manera inmediata, porque en cada momento está eligiendo,

47 Marías, J., La felicidad humana, pp. 291 y 292.

48 Marías, J., El intelectual y su mundo, p. 22.

49 Marías, J. (2000). Tratado sobre la convivencia. Concordia sin acuerdo. Barcelona: Martínez Roca, p. 155. 
decidiendo y haciendo. Marías solía fijarse mucho en la cara de una persona para ver qué comunica, cómo viene al encuentro e intuir si es confiable o no. Él buscaba la concordancia entre la vida personal y la vida pública; entre la manera de vivir de cada cual y la convivencia llevada a cabo con autenticidad, sin abandono de la verdad. Con solo ver el rostro, Marías estaba muy seguro que se podía descubrir, quién es alguien; la clave radicaba en tomar en serio lo que se ve y se oye. La responsabilidad de los hombres de menester intelectual no está tanto en que las personas sepan muchas cosas y tengan éxito, sino que forjen su vida con moralidad, haciendo y buscando lo mejor, dándose cuenta de cómo están viviendo, cómo están sintiendo y lo que hay que hacer para vivir y convivir de otra manera. Soto, reflexionando sobre la amistad como una forma de vida, manifesta un par de ideas que invitan a ir más allá de los aspectos cognoscitivos de la enseñanza:

«La primera es que la amistad es la unión de los pensamientos, de los ideales, de gustos y quereres, unión sostenida por la virtud y la sabiduría. La segunda es que donde reina la amistad no hay lugar para las pasiones torpes, ni para los vicios, ni el egoísmo, ni la vileza, ni la codicia, ni la ambición, ni la mala fe, ni la deslealtad, ni la infidelidad, ni la infamia» ${ }^{50}$.

La amistad es otro ingrediente para que la vida alcance niveles admirables; si esta es cultivada entre profesores y alumnos, otro mundo es posible. En el que ahora estamos instalados, es desorientador. Hay un empobrecimiento de la vida, por el lado que se lo vea, incluso da la impresión de que la moralidad no tiene que ver con la vida, siendo necesario educar los sentimientos y convivir cercanamente. En este afán, la amistad es el vector para concretarlo, en ella entra en juego la persona entera. Marías es un referente en esto, en el Prólogo de su obra Historia de la filosofía, escrito en 1965 y más pulidamente en Memorias de una vida presente (1978), narra la vivencia de la amistad que tuvo con un grupo de sus compañeras cuando fue requerido por ellas para que les ayudara a preparar un «examen intermedio», «con frecuencia los domingos, dos o tres horas por la mañana». Escribe Marías:

«Las muchachas tuvieron considerable éxito en los exámenes, con no poca sorpresa de los profesores; al año siguiente, algunas más, que tenían pendiente el mismo examen, me pidieron que volviera a organizar el curso; las más interesadas eran, sin embargo, las que ya lo habían aprobado y querían seguir asistiendo a aquellas clases de filosofía. Lo más interesante era que las chicas, que eran encantadoras e inteligentes, no me tenían ningún respeto, porque yo era un estudiante como ellas; no cabía usar el argumento de autoridad; exigían entender por qué eran las cosas así, por qué tal filósofo pensaba una teoría y por qué al siguiente le parecía inadmisible. Es decir, para que lo entendieran todo, tenía que entenderlo primero yo. No es para dicho el esfuerzo que tenía que hacer; pero, en primer lugar, lo pasábamos muy bien: era una delicia ver a aquellas muchachas curiosas, con cabezas claras, un poco

50 Soто, G., «La filosofía como forma de vida», en: Escritos, No. 39, Vol. 17, 2009, pp. 542-576. 
irónicas, tratando de penetrar en la filosofía. Nadie, ni siquiera mis maestros, me había enseñado tanto como aquellas chicas» ${ }^{51}$.

La actitud de Marías sorprende, siendo aún estudiante universitario, comprendió el sentido ético en la docencia y el gozo de la amistad. Su tarea consistió en filosofar, decir la verdad y manifestar respeto a sus compañeras. Eran muy estudiosas, Marías debía dar razones, explicar con claridad y no solamente transmitir conocimientos; vislumbrando desde ya, lo que vendría a futuro, una vida intelectual creadora y un hacer filosófico basado en la indagación, la comprensión de lo que pensaban los filósofos y clarificación de las discrepancias que había entre ellos. Esta experiencia académica le permitió aprender muchas cosas que no había recibido de sus maestros; algo que suele suceder a todos al dar los primeros pasos en el ejercicio de la profesión, desde luego con distintas experiencias que contar. La de Marías es extraordinaria; siendo muy joven, por el año 1933 a los diecinueve años de edad, cuando empezó a enseñar filosofía a sus compañeras universitarias, ya tuvo sumamente claro la aplicación del principio de la razón histórica en el hacer filosófico. Había comprendido el legado de su maestro Ortega para abordar los grandes problemas filosóficos y se dio cuenta de que por aquella época no había libros de Historia de la Filosofía que estudiasen a los filósofos según las épocas: griegos, medievales, modernos, contemporáneos. Sus maestros Zubiri, Morente, Gaos, Ortega, enseñaron filosofía sin hacer distinción de épocas, pero con exigencias adicionales: leer las obras de los filósofos en sus lenguas originales, estudiar y comentar sin huella de «nacionalismo» ni "provincialismo ${ }^{52}$. Estrategias pedagógicas que permiten no solamente pensar sino también escribir con creatividad y más allá de la propia circunstancia y a la altura de los tiempos como decía Ortega. Para Marías:

«Una historia de la filosofía sólo puede hacerse filosóficamente, reconstituyendo la serie íntegra de las filosofías del pasado desde una filosofía presente capaz de dar razón de ellas; y no excluirlas como errores superados, sino incluirlas como sus propias raíces ${ }^{53}$.

El academicismo filosófico no posibilita la innovación; tiende a quedarse en lo pasado sin rescatar lo valioso para las generaciones venideras, no cuestiona, no justifica, separa razón y vida. Ortega fue el artífice de fusionarlos y dar a la filosofía un nuevo método de indagación de la realidad: la razón vital. Un descubrimiento que salió de la idea de superar el realismo y el idealismo que imperaba en España y en toda Europa. Para que esto ocurra, Ortega asumió el desafío de que el hombre entienda de otra manera su relación con las cosas y con los demás. En su obra ¿Qué es filosofía?, expone lo siguiente al respecto:

51 Marías, J., Historia de la filosofía, xxxvi y xxxvii; MARías, J. (1989). Una vida presente: Memorias, 2 (1951-1975). Madrid: Alianza, p.104.

52 Marías, J., Historia de la filosofía, xxxiv y xxxv.

53 MARÍAs, J., Historia de la filosofía, xxxiii. 
«Para los antiguos, realidad, ser, significaba “cosa”; para los modernos, ser significaba, "intimidad, subjetividad"; para nosotros, ser significa "vivir" — por tanto-, intimidad consigo y con las cosas. (...) La existencia de las cosas como existencia independiente de mí es problemática, por consiguiente, abandonamos la tesis realista de los antiguos. Es, en cambio, indudable que yo pienso las cosas, que existe mi pensamiento y que, por tanto, la existencia de las cosas es dependiente de mí, es mi pensarlas; esta es la porción firme de la tesis idealista. Por eso la aceptamos pero, para aceptarla, queremos entenderla bien y nos preguntamos: ¿En qué sentido y modo dependen de mí las cosas cuando las pienso - qué son las cosas, ellas cuando digo que son solo pensamientos míos? El idealismo responde: las cosas dependen de mí, son pensamientos en el sentido de que son contenidos de mi conciencia, de mí pensar, estados de mi yo. Esta es la segunda parte de la tesis idealista y es la que no aceptamos. (...) Mientras este teatro sea este teatro, no puede ser un contenido de mi yo. Mi yo no es extenso ni es azul y este teatro es extenso y es azul. Lo que yo contengo y soy es solo mi pensar o ver el teatro, mi pensar o ver la estrella, pero no aquel ni esta. (...) Es falso, pues, que la conciencia sea algo cerrado, un darse cuenta solo de sí misma, de lo que tiene en su interior. Al revés, yo me doy cuenta de que pienso cuando, por ejemplo, me doy cuenta de que veo o pienso una estrella; y entonces de lo que me doy cuenta es de que existe dos cosas distintas, aunque unidas la una con la otra: yo que veo la estrella y la estrella que es vista por mí. (...) El ser del mundo ante mí es —diríamos- un funcionar sobre mí, y, parejamente, el mío sobre él. Por esto - una realidad que consiste en que un yo vea un mundo, lo piense, lo toque, lo ame o deteste, le entusiasme o le aconseje, lo transforme y aguante y sufra, es lo que desde siempre se llama "vivir", "mi vida", "nuestra vida", la de cada cual. Retorceremos, pues, el pescuezo a los venerables y consagrados vocablos existir, coexistir y ser, para en vez de ellos, decir: lo primario que hay en el Universo es "mi vivir" y todo lo demás lo hay, o no lo hay, en mi vida, dentro de ella» ${ }^{54}$.

La intuición de Ortega modifica la concepción del hombre y su relación con el mundo, sostenida por la tradición filosófica por largos siglos. Salta a la vista que su novedad filosófica es la vida: «lo que somos y lo que hacemos: es, pues, de todas las cosas la más próxima a cada cual» ${ }^{55}$. No se queda con la visión del hombre y del mundo de los filósofos griegos, orientado a las cosas; así como tampoco con el idealismo de época moderna que pone mayor énfasis en la racionalidad humana con Descartes a la cabeza (siglo XVII). Con Ortega la filosofía dio un giro hacia la vida humana como "realidad radical» inmediata; ahora, el eje es la propia vida, es decir, «mi vida», la vida de cada cual para hacer algo con las cosas y no a la inversa como está ocurriendo en la actualidad.

La razón es parte de la vida, no se da por separado, siempre pensamos en la vida; Marías advierte que la filosofía ha tardado unos dos mil quinientos años en darse cuenta de aquello; a su juicio, considera que han aportado a la comprensión de la vida humana: Dilthey, Ortega y Heidegger. Él mismo

54 Ortega y Gasset. ¿Qué es filosofía?, pp. 216- 221.

55 Ortega y Gasset. ¿Qué es filosofía?, p. 225. 
aclara en su Introducción a la filosofía, que trata esta cuestión basándose en la filosofía de Ortega, entonces descubre que no es lo mismo decir mi vida que la vida. Escribe Marías:

«Yo me encuentro viviendo, me encuentro en la vida y en ella con todas las cosas con que en cualquier forma o manera me encuentro o me puedo encontrar. Pero al decir mi vida tengo que guardarme, una vez más, de introducir ninguna teoría, para atenerme a la nuda realidad, tal como la hallo; es posible que la vida sea una operación de estructura determinada, que tenga principios, que tenga comunidad con el modo de ser de otros entes; todo esto son teorías - tal vez verdaderas- acerca de la realidad que es la vida; ésta es, simplemente, «lo que hacemos y lo que nos pasa», en expresión de Ortega; mejor aún, por lo pronto, lo que hago y lo que me pasa, en primera persona de singular del presente de indicativo - que son, no se olvide, el tiempo y el modo de lo real.

Y lo que me pasa es ante todo, que me encuentro, aquí y ahora, en una circunstancia, y que tengo que hacer algo con ella para vivir. Me pasa, pues, que tengo que hacer algo; el "tener que" da su peculiar pasividad a la vida, la cual me es dada, en la cual me encuentro sin haber intervenido yo ni haber sido consultado; pero esa pasividad me remite precisamente a una actividad, porque la vida, que me es dada, no me es dada hecha, sino al contrario, me es dada por hacer, me es dada como quehacer o tarea. Yo me encuentro, por tanto, ya en la vida, y ésta es anterior a mí y a las cosas que encuentro, en el sentido de que encuentro las cosas y a mí mismo en la vida, y el hallazgo del propio yo y de ellas es subsecuente al vivir ${ }^{56}$.

La razón vital permite indagar e interpretar la vida humana desde una perspectiva distinta a la tradición centrada en el estudio del ser, la sustancia ${ }^{57}$. La vida humana no es «algo» o «cosa» sino «alguien», se trata de «mi vida», de «nuestra vida», «la de cada cual» como lo manifiestan Ortega y Marías. Se trata de Yo viviendo en el mundo con las cosas y haciendo que estas sean, «de ahí que la filosofía sea una posibilidad a la que el hombre llega cuando siente la inexorable necesidad de dar razón del mundo y de la vida» ${ }^{58}$.

Como vemos, razón y vida son dos cuestiones inseparables porque son parte constitutiva del hombre. La una orienta a la otra para tomar decisiones y forjar la vida que pretende vivir en relación con los demás. Esto no es un descubrimiento reciente; el hombre siempre ha sido comunidad y ha razonado para transformarse y transformar el mundo en que vive. "Por tanto, podemos decir, con todo rigor, que la razón es la vida humana. Y esto explica a su vez que vivir sea necesariamente dar razón de lo que se hace en cada instante, esto es, hacer en este momento algo determinado, en vista de la totalidad de mi vida ${ }^{59}$.

56 MARÍAS, J., Introducción a la filosofía, pp. 229 y 230.

57 Restrepo, C., La vida humana. Biografía y estructura empírica, p. 61.

58 Fernández OchoA, L., «El sentido del quehacer filosófico en Julián Marías» en Ana María Araujo, comp. Julián Marías: un pensador de nuestro tiempo, Colombia: Universidad de la Sabana, pp. 2016, 35.

59 MARías, J., Introducción a la filosofía, p. 207. 
La razón vital tiene que ver con el descubrimiento y realización de la vocación. Marías manifiesta:

«Cuando la vida se hace desde el propio yo, cuando el hombre es fiel a esa voz que lo llama a ser una cosa determinada y que por eso recibe el nombre de vocación, es vida auténtica; cuando el hombre se abandona a lo tópico y recibido, cuando es infiel a su íntima y original vocación, falsea su vida y la convierte en inauténtica ${ }^{60}$.

Marías asumió su vida intelectual con autenticidad, rigor, nuevos puntos de vista y «visión responsable» de la realidad. Él pensaba que: «La inteligencia consiste primariamente en abrirse a las cosas y dejar que la realidad penetre en nuestra mente, en nuestra vida. Es un asunto de amor ${ }^{61}$. Quien ama a su vocación, hace que las cosas se hagan con cortesía y de distinta manera e incluso que las obras escritas continúen vigentes aún después de muerto. Es un proyecto de vida, libremente aceptado. Con razón, en las obras de Marías, sin dejar de lado el pensamiento orteguiano, encontramos contenidos con sentido profundo de humanidad y afectividad, el deseo de que otros lo lean y temas de diversa índole para tratar con un nuevo esplendor desde la perspectiva propia. Y algo importante: nunca deja de lado el suceso histórico y es un potencial en todas sus obras.

\section{BiBLIOGRAFÍA}

Barsallo, A. (2014). «Marías, crítico de cine personalista». En: Cuenta y Razón, No. 30, 37. http://cuentayrazon.com/wp-content/uploads/2016/05/revista30.pdf

Fernández Ochoa, L. (2016). «El sentido del quehacer filosófico en Julián Marías». En: Ana María Araújo, comp. Julián Marías: un pensador de nuestro tiempo. Colombia: Universidad de la Sabana.

Marías, J. (1956). El intelectual y su mundo. Buenos Aires: Atlántida.

Marías, J. (2003). Cervantes clave española. Madrid: Alianza Editorial.

Marías, J. (1962). Introducción a la filosofía. Madrid: Revista de Occidente.

Marías, J. (1958). El oficio del pensamiento. Ensayos. Madrid: Nueva Almagro.

Marías, J. (1970). Antropología Metafísica. La estructura empírica de la vida humana. Madrid: Revista de Occidente.

Marías, J. (2013). «In Memorian. Cómo veo a José Manuel Blecua». En: Cuenta y Razón, No. 28, 124. http://cuentayrazon.com/wp-content/uploads/2016/05/revista28.pdf

Marías, J. (1998). Sobre el cristianismo. Barcelona: Editorial Planeta.

Marías, J. (1969). Miguel de Unamuno. La Escuela de Madrid. La imagen de la vida humana. Madrid: Revista de Occidente, Tomo V.

Marías, J. (1980). Historia de la filosofía. Madrid: Revista de Occidente.

Marías, J. (1995). Tratado de lo mejor. La moral y las formas de la vida. Madrid: Alianza. Marías, J. (1954). Idea de la metafísica. Buenos Aires: Columba.

Marías, J. (1996). Persona. Madrid: Alianza Editorial.

60 MARÍAs, J., Historia de la filosofía, p. 445.

${ }^{61}$ MARíAs, J., «In Memorian», p. 125. 
Marías, J. (1989). La felicidad humana. Madrid: Editorial.

Marías, J. (1992). La educación sentimental. Madrid: Alianza Editorial.

Marías, J. (2000). Tratado sobre la convivencia. Concordia sin acuerdo. Barcelona: Martínez Roca.

Marías, J. (1989). Una vida presente: Memorias, 2 (1951-1975). Madrid: Alianza.

Ortega y Gasset, J. (1959). El libro de las misiones. Madrid: Espasa-Calpe.

Ortega y Gasset, J. (1969). ¿Qué es filosofía? Madrid: Revista de Occidente.

Raley, H. (1977). La visión responsable-La filosofía de Julián Marías, trad. César Armando Gómez. Madrid: Espasa.

Raley, H. (1997). Julián Marías: una filosofía desde dentro. Madrid: Alianza Editorial.

Restrepo, C. (2013). La vida humana. Biografía y estructura empírica. Medellín: Universidad Pontifica Bolivariana.

Soto, G. «La filosofía como forma de vida». Y en: Escritos, No. 39, Vol. 17, 2009.

Universidad Católica de Cuenca - Ecuador José RaUl Asimbaya Socasi

Studium Theologicum Franciscanum "Cardenal Echeverría"

Universidad Pontificia Bolivariana - Colombia

Conrado de Jesús GiRaldo Zuluaga

[Artículo aprobado para publicación en enero de 2019] 